\title{
A New Fixed Switching Frequency Direct Torque Controlled PMSM Drives with Low Ripple in Flux and Torque
}

\author{
Tole Sutikno ${ }^{1,2}$, Nik Rumzi Nik Idris ${ }^{1} \&$ Auzani Jidin $^{3}$ \\ ${ }^{1}$ Dep. of Energy Conversion, Universiti Teknologi Malaysia (UTM), Johor, Malaysia \\ ${ }^{2}$ Dep. of Electrical Engineering, Universitas Ahmad Dahlan (UAD), \\ Yogyakarta, Indonesia \\ ${ }^{3}$ Dep. of Power Electronics and Drives, Universiti Teknikal Malaysia Melaka, Malaysia \\ E-mail: tole@ee.uad.ac.id
}

\begin{abstract}
Direct Torque Control (DTC) has gained popularity for development of advanced motor control due to its simplicity and offers fast instantaneous torque and flux controls. However, the conventional DTC which is based on hysteresis controller has major drawbacks, namely high torque ripple and variable inverter switching frequency. This paper presents an improved switching strategy for reducing flux and torque ripples in DTC of PMSM drives; wherein the torque hysteresis controller and the look-up table used in the conventional DTC are replaced with a constant frequency torque controller (CFTC) and an optimized look-up table, respectively. It can be shown that a constant switching frequency is established due to the use of the CFTC while the reduction of torque and flux ripples is achieved mainly because of the selection of optimized voltage vector (i.e. with an optimized look-up table). This paper also will explain the construction of DTC schemes implemented using MATLAB-Simulink blocks. Simulation results were shown that a significant reduction of flux and torque ripples which is about $90 \%$ can be achieved through the proposed DTC scheme.
\end{abstract}

Keywords: DTC; PMSM; Fixed Switching Frequency; MATLAB/Simulink.

\section{$1 \quad$ Introduction}

In recent years, it had shown significant interest to develop Permanent Magnet Synchronous Machine (PMSM) control schemes for high performance applications such as traction drive, electric vehicle and ship electric propulsion. PMSM has gained popularity to be adapted in many electric motor applications due to the fact that it offers high torque density (i.e. $\mathrm{Nm} / \mathrm{kg}$ ), and high efficiency as compared to that of induction machine. Basically, the control methods of PMSM can be divided into two methods (similar to that of using induction machine) as follows; 1) scalar control also knows as 'volt per Hertz' method which is simple to implement, however it gives poor dynamic performance, 2) vector control, i.e. Field Oriented Control (FOC) or Direct Torque Control

Received May $9^{\text {th }}, 2009$, Revised July, 2009, $2^{\text {nd }}$ revision May $31^{\text {st }}, 2010$, Accepted for publication May $20^{\text {th }}$, 2011.

Copyright (C) 2011 Published by LPPM ITB \& PII, ISSN: 1978-3051, DOI: 10.5614/itbj.eng.sci.2011.43.3.2 
(DTC) which is based on the instantaneous space vector quantity (i.e. phase of flux, current and voltage) control [1-3].

The latter method is preferable since it can produce superior control performance in steady state and dynamic conditions. Among both schemes in the latter method, Direct Torque Control (DTC) provides more advantages such as excellent dynamic behavior, less parameter dependency, no speed sensor and simple structure. The DTC method was proposed by Takahashi [4] and Depenbrock [5] for induction motor drives in the middle of 1980's; it also was developed in 1990's for PMSM drive [6]. A quick response of instantaneous torque and flux control was established using a decoupled torque-flux control without reference frame transformer and current controller.

However, the hysteresis controllers used in the conventional DTC gives two major drawbacks which are variable switching frequency and high torque ripple. Theoretically, a reduction of torque ripple can be accomplished by reducing the bandwidth of torque hysteresis comparator such that the torque ripple is restricted to be regulated within its band. In such a way, a high speed processor must be utilized in which normally requires an expensive controller board (i.e. a powerful controller board DSPACE1104) and high-cost design in developing Verilog or VHDL code (i.e. in the case of using FPGA). Although, the use of high speed processor in implementing discrete hysteresis controllers still does not guarantee to perform the DTC at a constant switching frequency. This is because the slope of torque may vary on operating conditions (i.e. speed, load torque, flux linkages and etc.), which in turns causes the switching in the torque hysteresis controller that is directly affected the inverter switching frequency is unpredictable.

A common approach to minimize the torque ripple and at the same time provides a constant switching frequency is the use of Space Vector Modulation (SVM) technique [1]. The DTC scheme that works with a SVM is normally referred to as DTC-SVM. In DTC-SVM, a major modification is required on the original structure of DTC where, a standard look-up table and hysteresis controllers are replaced with space vector modulator and estimation of reference voltage. Hence, this will complicate the structure of DTC. Furthermore, to solve the SVM itself, it requires a fast speed of processor to synthesize the estimated voltage and to provide more switching state numbers in order to have great reduction of torque ripple.

This paper presents an optimized look-up table (i.e. voltage vector selection) and a Constant Frequency Torque Controller (CFTC) proposed in [7] to achieve constant switching frequency and significant reduction of torque and flux ripples in DTC of PMSM drives. It had been reported in [8] that a great 
reduction of torque ripple can be achieved by enlarging the carrier frequency in CFTC even operated at limited sampling DSP. However, the method does not guarantee to keep proper control of torque particularly at very low speed and near the base speed operations, where the crossover frequency of the PI control in CFTC is determined at the worst conditions. The proposed method, on the other hand makes an effort to select optimized voltage vectors (i.e. from the modified look-up table) with the use of CFTC in DTC to minimize the flux ripple and hence the torque ripple. The advantages of the proposed method (i.e. combination of CFTC and the modified look-up table) will be highlighted by studying the effect of the ripples performance at three different sets of look-up table. The effectiveness of the method to minimize the torque and flux ripples will be verified through MATLAB/Simulink simulation results.

\section{The Conventional DTC of PMSM}

Figure 1 shows a simple structure of the conventional DTC for PMSM drive.

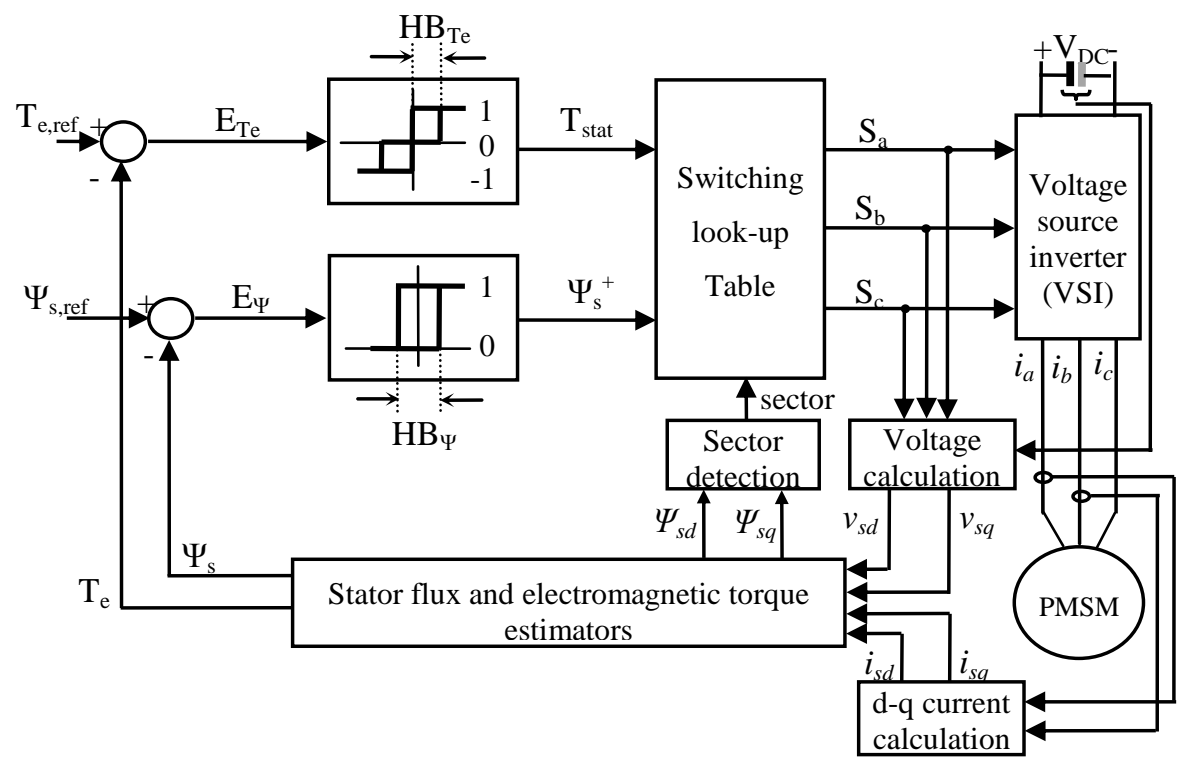

Figure 1 The conventional DTC scheme of PMSM drive system.

A decoupled control structure that permits a quick torque and flux dynamic responses is established wherein the flux and torque are controlled independently using two-level and three-level hysteresis comparators. The output of the comparators and sector information are used to index a look-up table to select appropriate voltage vector to control both stator flux and torque, simultaneously. 
The effects of the selection of optimized voltage vectors (i.e. from the modified look-up table) on torque and flux ripples can be investigated by performing the DTC at three-different set of look-up table $[9,10]$ as follows:

\subsection{Eight Switching States Table (Switching Table 1)}

The switching table (Table 1) was proposed in [11] where the optimized voltage vector is selected based on torque and flux error status and also information of flux position. The table provides two zero voltage vectors and six nonzero voltage vectors.

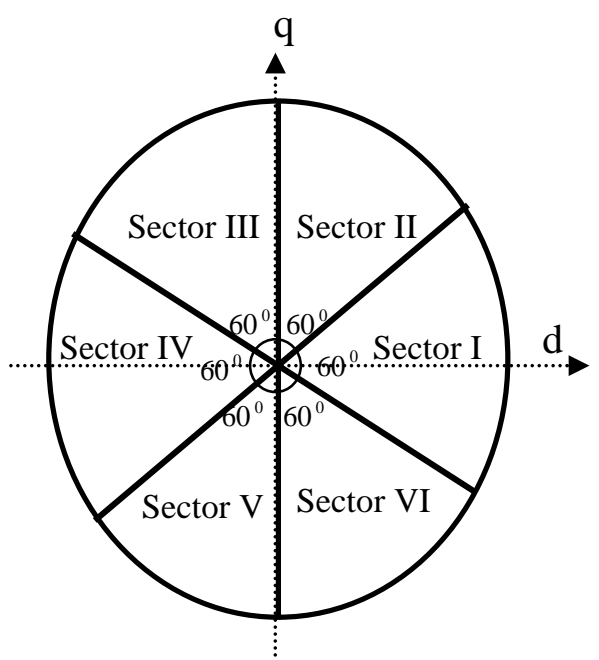

(a)

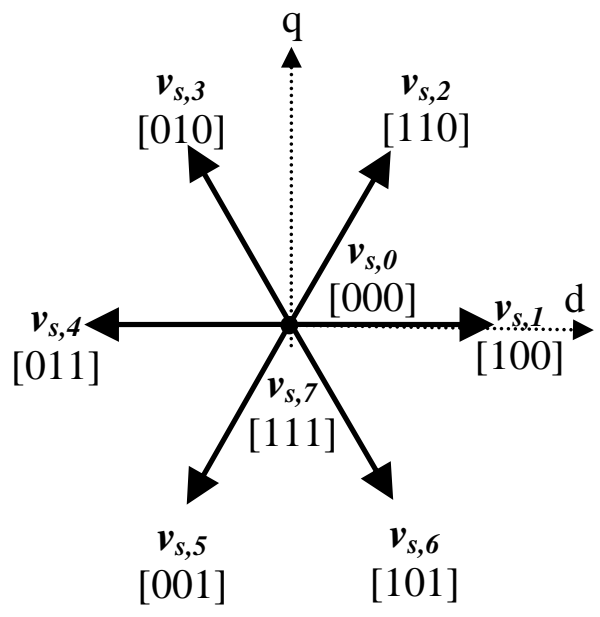

(b)

Figure 2 Voltage vectors of the 3-phase VSI and the six stator flux position sectors; (a) Definition of six sectors of the stator flux plane, (b) Voltage space vectors of a 3-phase inverter with the corresponded switching states.

In steady state operation; the non-zero voltage vectors are used to control flux either to increase the flux (i.e. $C_{\Psi}=1$ ) or decrease the flux (i.e. $C_{\Psi}=0$ ), according to the flux position, and at the same time is used to increase the torque (i.e. $\mathrm{C}_{\mathrm{T}}=1$ ), otherwise the zero voltage vectors are switched (i.e. $\mathrm{C}_{\mathrm{T}}=0$ ) whenever the output torque satisfies to its demand. 
Table 1 Eight Switching States Table (Switching Table 1).

\begin{tabular}{cccccccc}
\hline $\mathbf{C}_{\boldsymbol{\psi}}$ & $\mathbf{C}_{\mathbf{T}}$ & $\begin{array}{c}\text { Sector } \\
\mathbf{1}\end{array}$ & $\begin{array}{c}\text { Sector } \\
\mathbf{2}\end{array}$ & $\begin{array}{c}\text { Sector } \\
\mathbf{3}\end{array}$ & $\begin{array}{c}\text { Sector } \\
\mathbf{4}\end{array}$ & $\begin{array}{c}\text { Sector } \\
\mathbf{5}\end{array}$ & $\begin{array}{c}\text { Sector } \\
\mathbf{6}\end{array}$ \\
\hline 1 & 1 & $\mathrm{~V}_{2}$ & $\mathrm{~V}_{3}$ & $\mathrm{~V}_{4}$ & $\mathrm{~V}_{5}$ & $\mathrm{~V}_{6}$ & $\mathrm{~V}_{1}$ \\
1 & 0 & $\mathrm{~V}_{7}$ & $\mathrm{~V}_{0}$ & $\mathrm{~V}_{7}$ & $\mathrm{~V}_{0}$ & $\mathrm{~V}_{7}$ & $\mathrm{~V}_{0}$ \\
0 & 1 & $\mathrm{~V}_{3}$ & $\mathrm{~V}_{4}$ & $\mathrm{~V}_{5}$ & $\mathrm{~V}_{6}$ & $\mathrm{~V}_{1}$ & $\mathrm{~V}_{2}$ \\
0 & 0 & $\mathrm{~V}_{0}$ & $\mathrm{~V}_{7}$ & $\mathrm{~V}_{0}$ & $\mathrm{~V}_{7}$ & $\mathrm{~V}_{0}$ & $\mathrm{~V}_{7}$ \\
\hline
\end{tabular}

\subsection{Six Switching States Table (Switching Table 2)}

The switching table that provides six switching states as used in $[6,11,12]$ is given in Table 2. The table provides only non-zero voltage vectors in controlling both stator flux and torque. In steady state operation; the non-zero voltage vectors are used to control flux either to increase the flux (i.e. $\mathrm{C}_{\Psi=1}$ ) or decrease the flux (i.e. $\mathrm{C}_{\Psi=0}$ ), according to the flux position, and at the same time the forward non-zero voltage vector is used to increase the torque (i.e. $\mathrm{C}_{\mathrm{T}}=1$ ), otherwise the reverse non-zero voltage vectors are switched (i.e. $\mathrm{C}_{\mathrm{T}}=0$ ) whenever the output torque satisfies to its demand. Note that the application of non-zero voltage vectors in controlling the output torque causes a rapid torque change (i.e. higher torque slope) and hence results in higher switching frequency.

Table 2 Six-State Table (Switching Table 2).

\begin{tabular}{cccccccc}
\hline $\mathbf{C}_{\boldsymbol{\psi}}$ & $\mathbf{C}_{\mathbf{T}}$ & $\begin{array}{c}\text { Sector } \\
\mathbf{1}\end{array}$ & $\begin{array}{c}\text { Sector } \\
\mathbf{2}\end{array}$ & $\begin{array}{c}\text { Sector } \\
\mathbf{3}\end{array}$ & $\begin{array}{c}\text { Sector } \\
\mathbf{4}\end{array}$ & $\begin{array}{c}\text { Sector } \\
\mathbf{5}\end{array}$ & $\begin{array}{c}\text { Sector } \\
\mathbf{6}\end{array}$ \\
\hline 1 & 1 & $\mathrm{~V}_{2}$ & $\mathrm{~V}_{3}$ & $\mathrm{~V}_{4}$ & $\mathrm{~V}_{5}$ & $\mathrm{~V}_{6}$ & $\mathrm{~V}_{1}$ \\
1 & 0 & $\mathrm{~V}_{6}$ & $\mathrm{~V}_{1}$ & $\mathrm{~V}_{2}$ & $\mathrm{~V}_{3}$ & $\mathrm{~V}_{4}$ & $\mathrm{~V}_{5}$ \\
0 & 1 & $\mathrm{~V}_{3}$ & $\mathrm{~V}_{4}$ & $\mathrm{~V}_{5}$ & $\mathrm{~V}_{6}$ & $\mathrm{~V}_{1}$ & $\mathrm{~V}_{2}$ \\
0 & 0 & $\mathrm{~V}_{5}$ & $\mathrm{~V}_{6}$ & $\mathrm{~V}_{1}$ & $\mathrm{~V}_{2}$ & $\mathrm{~V}_{3}$ & $\mathrm{~V}_{4}$ \\
\hline
\end{tabular}

\subsection{Eight Switching States Table (Switching Table 3)}

The switching table that provides eight switching states as proposed in [4] is given in Table 3. The table provides two zero voltage vectors and six non-zero voltage vectors. The selection of voltage vectors is based on two digitized output of flux error status and three digitized output of torque error status. In steady state operation; the forward non-zero voltage vectors are used to control flux either to increase the flux (i.e. $C_{\Psi}=1$ ) or decrease the flux (i.e. $C_{\Psi}=0$ ), according to the flux position, and at the same time is used to increase the torque (i.e. $\mathrm{C}_{\mathrm{T}}=1$ ), otherwise the zero voltage vectors are switched (i.e. $\mathrm{C}_{\mathrm{T}}=0$ ) whenever the output torque satisfies to its demand. As the torque is satisfied, the torque error status $\mathrm{C}_{\mathrm{T}}$ will produce 0 to select the zero vectors and hence, this ideally will halt the flux. The continuous rotation of rotor flux linkage that 
follows the stator flux, as a result reduces the load angle (i.e. difference of angle between stator flux and rotor flux linkages) and also the output torque slowly. In such a way, the output torque ripples as well as inverter switching frequency can be reduced, but with the use of high speed processor. The output torque error status $\mathrm{C}_{\mathrm{T}}$ is equal to -1 whenever a sudden large negative torque error is encountered, particularly during a speed reversal. In this case, a rapid decrease of output torque is resulted by selecting reverse non-zero voltage vectors. Figure 3 depicts a two-level and a three-level hysteresis comparators that will produce $\mathrm{C}_{\mathrm{T}}=1,0$ and $\mathrm{C}_{\mathrm{T}}=1,0,-1$, respectively.

Table 3 Bipolar Torque / Eight-State Table.

\begin{tabular}{cccccccc}
\hline $\mathbf{C}_{\boldsymbol{\psi}}$ & $\mathbf{C}_{\mathbf{T}}$ & $\begin{array}{c}\text { Sector } \\
\mathbf{1}\end{array}$ & $\begin{array}{c}\text { Sector } \\
\mathbf{2}\end{array}$ & $\begin{array}{c}\text { Sector } \\
\mathbf{3}\end{array}$ & $\begin{array}{c}\text { Sector } \\
\mathbf{4}\end{array}$ & $\begin{array}{c}\text { Sector } \\
\mathbf{5}\end{array}$ & $\begin{array}{c}\text { Sector } \\
\mathbf{6}\end{array}$ \\
\hline 1 & 1 & $\mathrm{~V}_{2}$ & $\mathrm{~V}_{3}$ & $\mathrm{~V}_{4}$ & $\mathrm{~V}_{5}$ & $\mathrm{~V}_{6}$ & $\mathrm{~V}_{1}$ \\
1 & 0 & $\mathrm{~V}_{7}$ & $\mathrm{~V}_{0}$ & $\mathrm{~V}_{7}$ & $\mathrm{~V}_{0}$ & $\mathrm{~V}_{7}$ & $\mathrm{~V}_{0}$ \\
1 & -1 & $\mathrm{~V}_{6}$ & $\mathrm{~V}_{1}$ & $\mathrm{~V}_{2}$ & $\mathrm{~V}_{3}$ & $\mathrm{~V}_{4}$ & $\mathrm{~V}_{5}$ \\
0 & 1 & $\mathrm{~V}_{3}$ & $\mathrm{~V}_{4}$ & $\mathrm{~V}_{5}$ & $\mathrm{~V}_{6}$ & $\mathrm{~V}_{1}$ & $\mathrm{~V}_{2}$ \\
0 & 0 & $\mathrm{~V}_{0}$ & $\mathrm{~V}_{7}$ & $\mathrm{~V}_{0}$ & $\mathrm{~V}_{7}$ & $\mathrm{~V}_{0}$ & $\mathrm{~V}_{7}$ \\
0 & -1 & $\mathrm{~V}_{5}$ & $\mathrm{~V}_{6}$ & $\mathrm{~V}_{1}$ & $\mathrm{~V}_{2}$ & $\mathrm{~V}_{3}$ & $\mathrm{~V}_{4}$ \\
\hline
\end{tabular}

Although the conventional DTC scheme PMSM drive is an attractive proposition in its own right, this scheme has some drawback, such as [6]: variable switching frequency, torque and flux ripples, require of high sampling time, current and torque distortion and drift in flux estimator. In order to get an excellent performance, during last decade many researchers proposed some modifications of conventional DTC scheme (similar with modification techniques used in induction machine), for examples the use of new switching table, modification of topology of inverter, and modification of hysteresis controller.
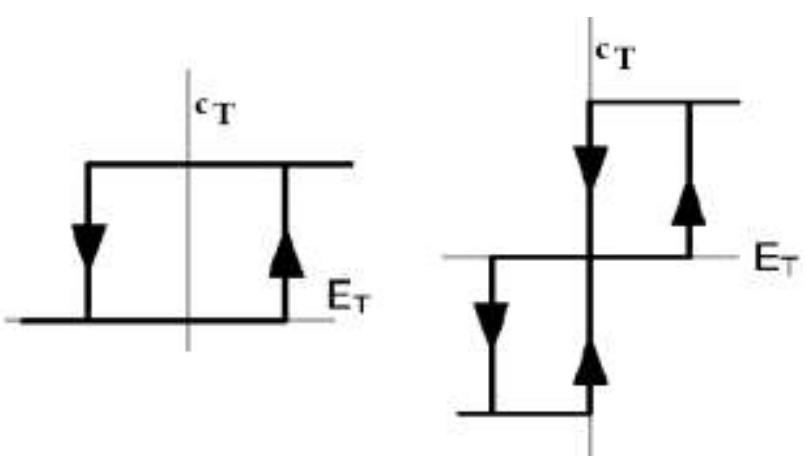

Figure 3 Two and Three Level Torque Hysteresis Controller Characteristics. 
Most modifications of DTC PMSM drive appointed above allow performance to be improved, but at the same time they lead to more complex schemes. In [7] a novel DTC scheme for induction motor with a pair of torque and flux controllers to replace the hysteresis-based controllers can significantly reduce torque and stator flux ripples, with the switching frequency is fixed at $10.4 \mathrm{kHz}$ and a more sinusoidal phase current. This DTC method is relatively fixed simple and quick response, so it can support operation of high performance induction machine drive. This paper presents an optimized fixed switching frequency torque controller (FSFTC) to improve performance of DTC of PMSM drives. The proposed controller utilizes combination of CFTC [7] and the modified look-up table. At the same time the simple control structure of a DTC drive by [4] will be retained.

\section{Torque Ripple Reduction Technique for DTC PMSM}

Although the DTC scheme is an attractive proposition in its own right, this conventional DTC for PMSM drive has some drawback. It stills lefts some problems, such as: variable switching frequency, torque and flux ripples, require of high sampling time, current and torque distortion and drift in flux estimator.

In order to get an excellent performance, many modifications of the basic switching table, hysteresis comparator and flux estimator of the conventional DTC (similar techniques those used in induction machine) have been proposed during last decade, as listed as follows:

1. Using new switching table

- Subdividing voltage vector [13-15]

- Variety of structure switching table [13,16,17]

- PWM (Pulse Width Modulation) [18]

- SVM (Space Vector Modulation) [19-21]

2. Modification of structure of inverter:

- Three level inverter [22]

- Matrix converter [21,23,24]

3. Modification of hysteresis controller

- Direct Reactive Energy and Torque (DRET) control method [25]

- Reference Flux Vector Calculator (RFVC) [17]

- Variable Structure Control (VSC) [26,27]

Due to some modification of the DTC techniques for PMSM above, the verification of the proposed methods had been simulated using 
MATLAB/Simulink. These researches above have shown that all contributions allow performance to be improved, but at the same time they lead to more complex schemes.

\section{The Proposed DTC Scheme for PMSM Drive}

The proposed DTC scheme of PMSM drive is shown in Figure 4. This scheme still uses hysteresis flux controller as in [4], but it uses fixed switching frequency torque controller model as like [7] was proposed for DTC of induction motor drive. The proposed torque controller consists of two triangular waveform generators, two comparators, and a Proportional Integral (PI) controller as shown in Figure 5. The two triangular waveforms $\left(\mathrm{C}_{\text {upper }}\right.$ and $\left.\mathrm{C}_{\text {lower }}\right)$ are asynchronous but out of phase with each other. In this research, simulations of six different DTC scheme sets have been carried out as follows: hysteresis DTC and proposed DTC scheme (with hysteresis flux controller and fixed switching frequency torque controller) was using switching table 1,2 , and 3.

The PMSM DTC simulation system is based on the MATLAB/Simulink 6.6 (R2007a). A block diagram of a proposed DTC system for PMSM is shown in Figure 6, which includes the $\mathrm{ABC}$ to $\mathrm{DQ}$ transformation, torque and flux estimator subsystem, etc. The ABC to DQ transformation and, torque and flux linkage estimator are respectively shown in the Figure 7 and 8.

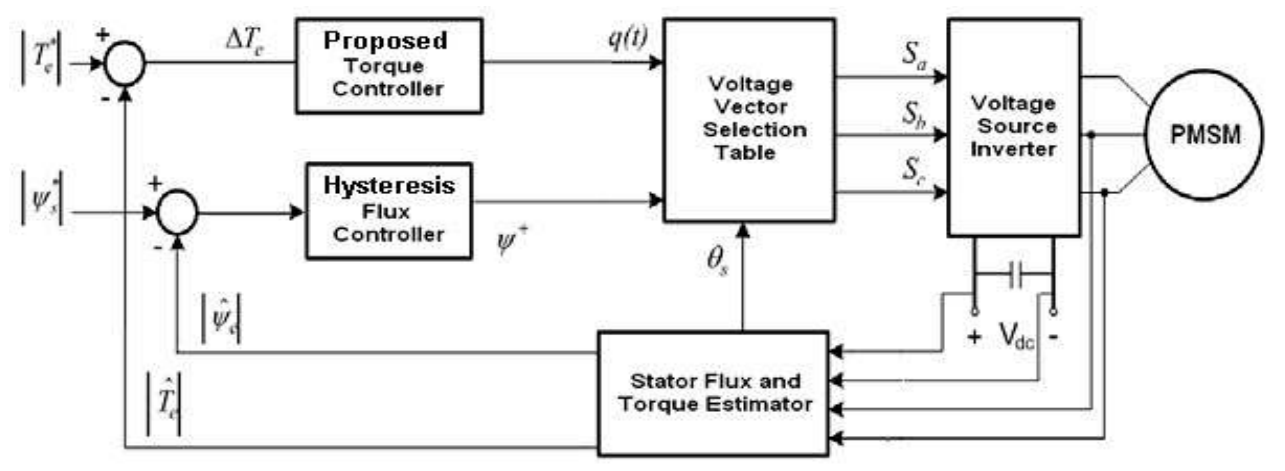

Figure 4 Proposed DTC Scheme of PMSM Drive System.

In the flux linkage estimator in Figure 8, we should not set the linkage initial value equal to zero, because the program can not run successfully in Simulink. So, in the flux estimator, it should set an initial value of integrator block gain as reported in [28]. In this paper, it is chosen -0.553. 


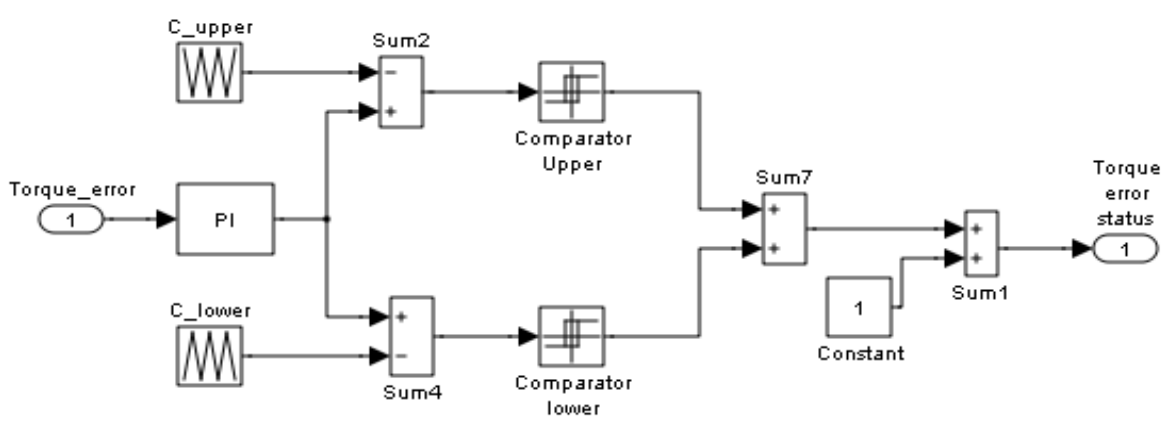

Figure 5 Proposed Torque Controller [7] with simple Modification.

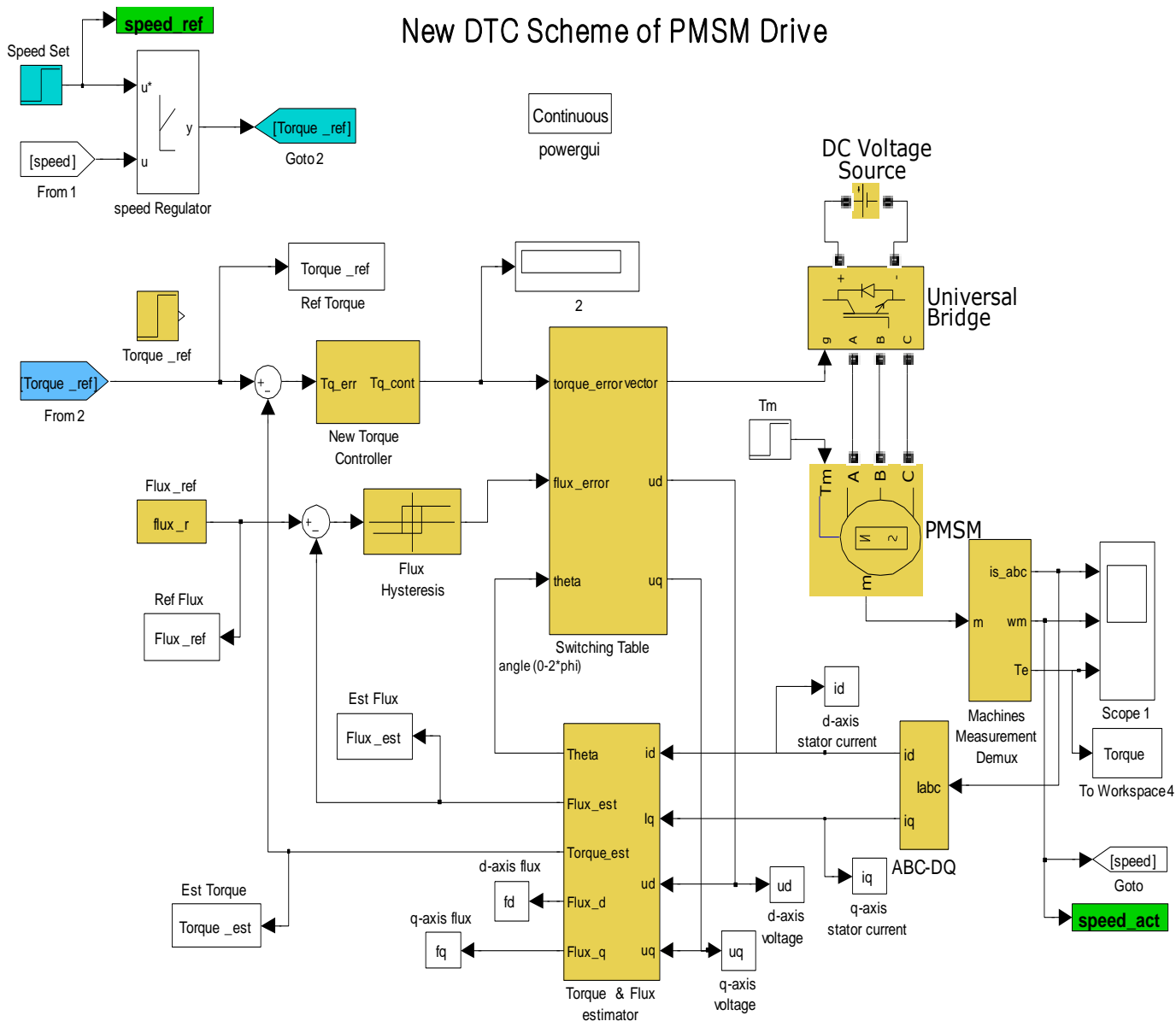

Figure 6 The overall system of the proposed DTC scheme for PMSM drives in Simulink Model. 


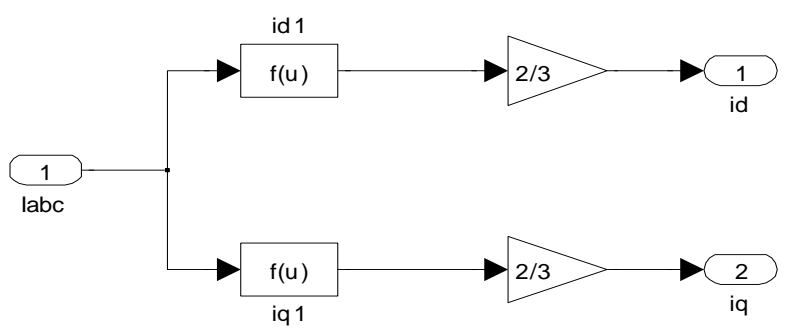

Figure 7 The ABC to DQ transformation.

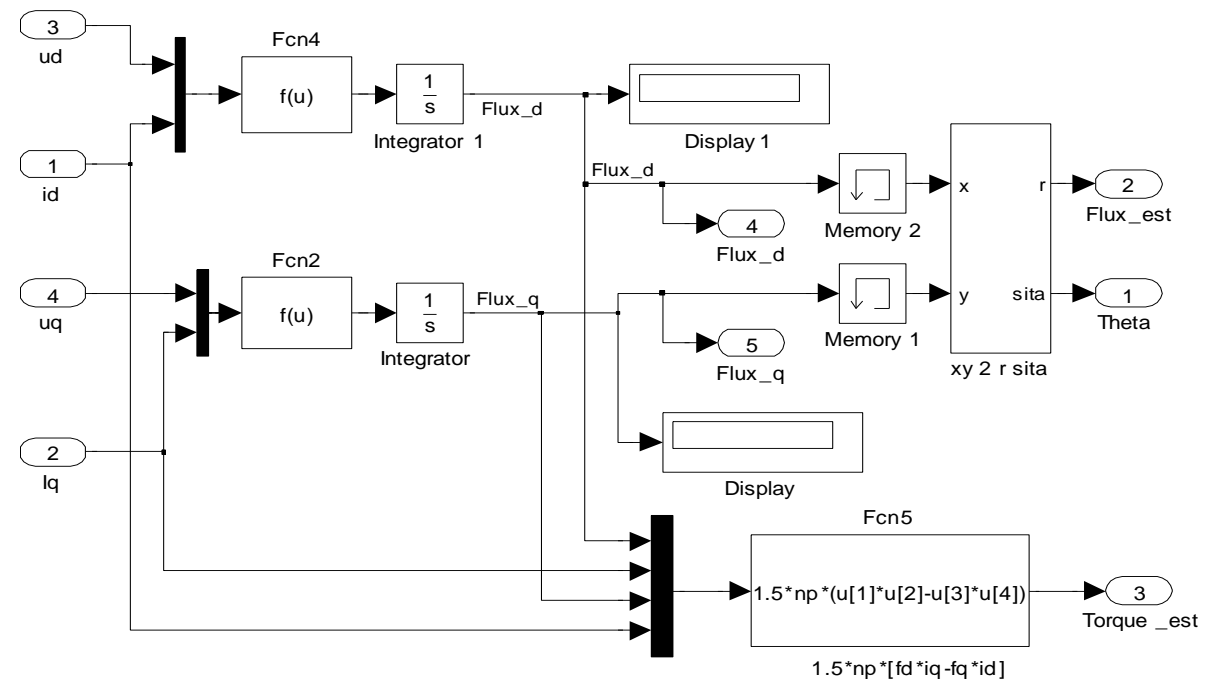

Figure 8 The torque and flux estimator.

The torque and flux estimator in Figure 8 are calculated with equation followed:

$$
\begin{aligned}
& \psi_{d}=\int\left(u_{d}-R_{s} i_{d}\right) d t+\psi_{d \mid t=0} \\
& \psi_{q}=\int\left(u_{q}-R_{s} i_{q}\right) d t+\psi_{q \mid t=0} \\
& \psi_{s}=\sqrt{\psi_{d}^{2}+\psi_{q}^{2}} \\
& T_{e}=\frac{3}{2} n_{p}\left(\psi_{s} \times i_{s}\right)=\frac{3}{2} n_{p}\left(\psi_{d} i_{q}-\psi_{q} i_{d}\right)
\end{aligned}
$$

where: $\mathrm{U}_{\mathrm{d}}=0.66667 \mathrm{Udc}\left(\mathrm{S}_{\mathrm{a}}-0.5 \mathrm{~S}_{\mathrm{b}}-0.5 \mathrm{~S}_{\mathrm{c}}\right)$

$$
\mathrm{U}_{\mathrm{q}}=0.57735 \mathrm{U}_{\mathrm{dc}}\left(\mathrm{S}_{\mathrm{b}}-\mathrm{S}_{\mathrm{c}}\right)
$$




\section{Simulation Results and Discussions}

The comparison of the electromagnetic torque response simulation under their hysteresis DTC schemes and proposed DTC scheme is shown in Figure 11.

Under Hysteresis torque controller

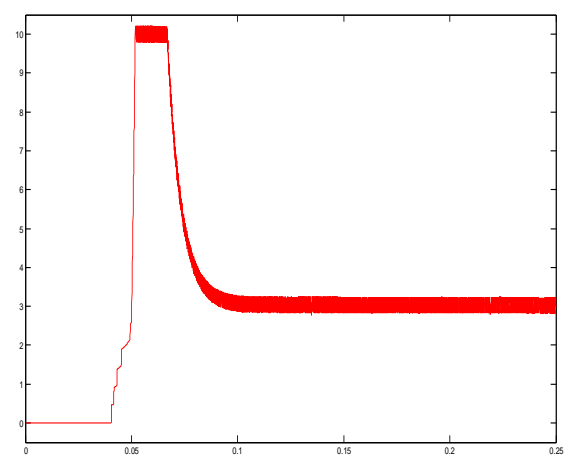

a. Using Table 1

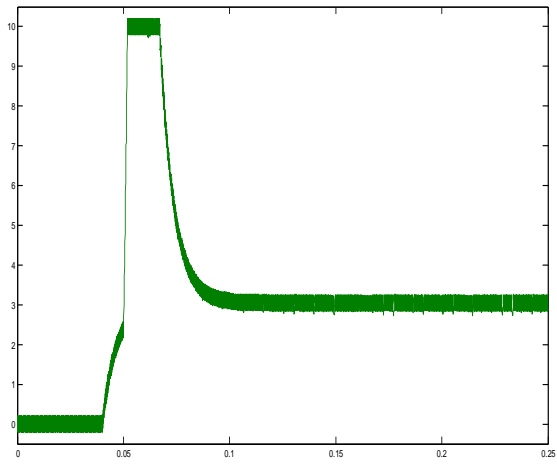

b. Using Table 2

\section{Under Proposed torque controller}

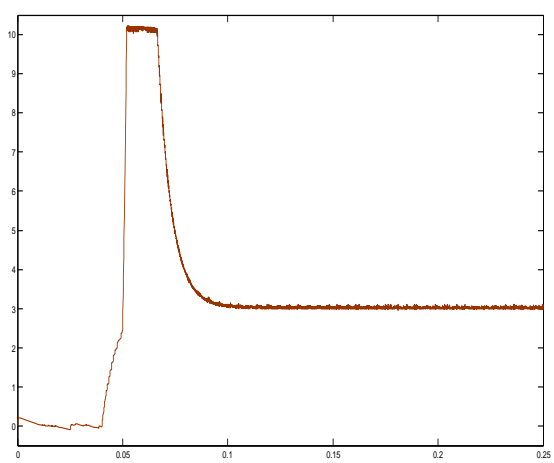

d. Using Table 1

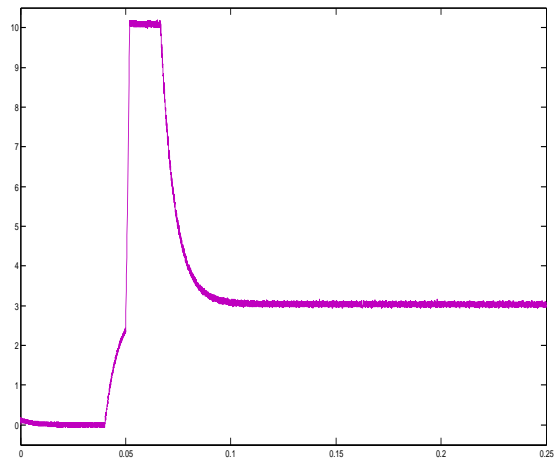

e. Using Table 2 
Under Hysteresis torque controller

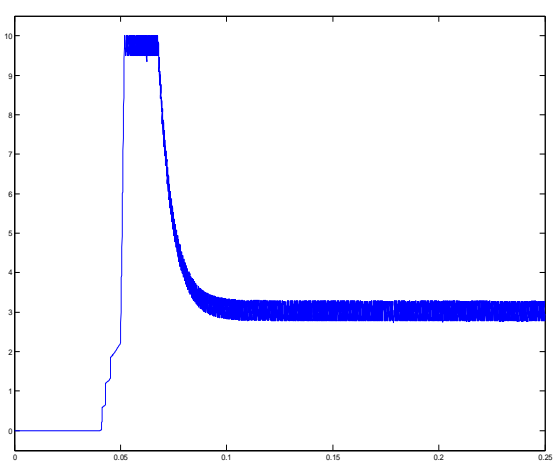

c. Using Table 3

\section{Under Proposed torque controller}

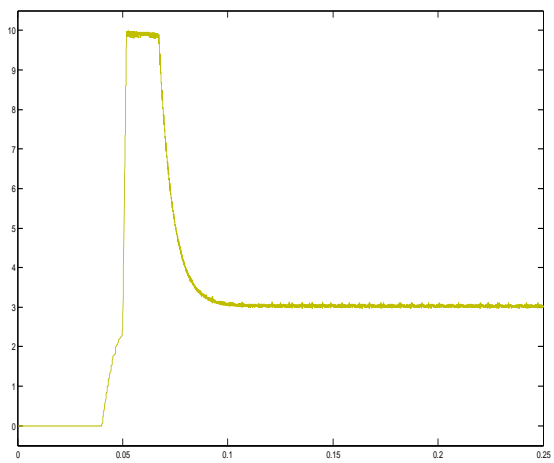

f. Using Table 3

Figure 11 The Comparison of Electromagnetic Torque Response Under Hysteresis DTC and Proposed DTC Scheme.

The Figure $11(\mathrm{a}, \mathrm{b}$, and $\mathrm{c})$ show response of torque ripple under hysteresis torque controller and Figure $11(\mathrm{~d}, \mathrm{e}$, and $\mathrm{f}$ ) show response of torque ripple under proposed torque controller. It is seen that the response of torque ripple under proposed torque controller is lower than under hysteresis torque controller for each using switching tables.

The detail of response torque ripple in steady state under proposed torque controller for each using switching tables is shown in Figure 12. It is seen, that the proposed DTC system for PMSM drive using switching Table 3 can reduce torque ripples up to $90 \%$ if it is compared under hysteresis using switching Table 1 as shown in Figure 12(d).

Next, the stator flux linkage trace from six different sets of DTC simulations for PMSM is show in Figure 13. It is shown that the proposed DTC system for PMSM can also reduce flux ripples, so the stator flux linkage is controlled better at the required value. The better performance is shown in Figure 13(f) (under proposed DTC scheme use switching Table 3).

The comparisons through simulations between hysteresis DTC scheme and proposed DTC scheme for PMSM drive have been done. The simulation based on MATLAB/Simulink in this research represented the behavior of DTC clearly and correctly. The simulation result has shown that the proposed DTC method for PMSM drive can reduce the ripple of torque and flux greatly. By this way, torque and flux ripple is smaller than those of conventional (hysteresis) DTC scheme. 


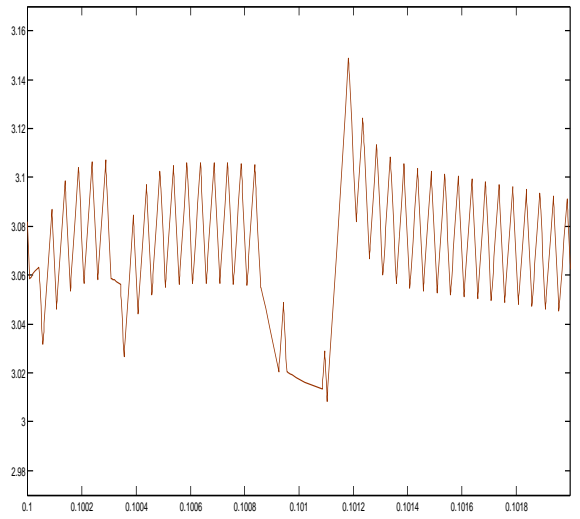

a. Using switching table 1 under proposed torque controller

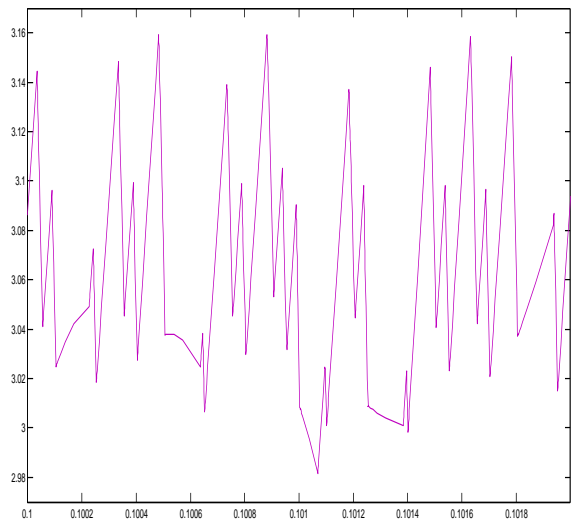

b. Using switching table 2 under proposed torque controller

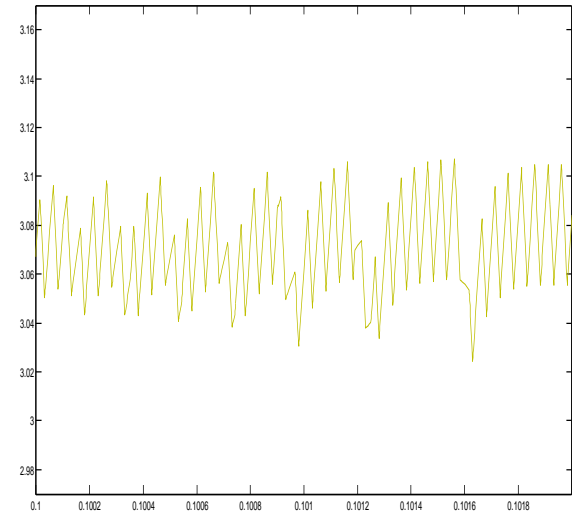

c. Using switching table 3 under proposed torque controller

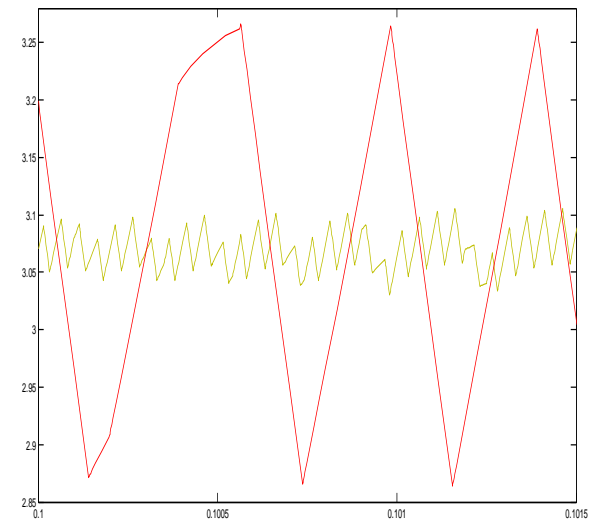

d. Using switching table 1 under hysteresis torque controller is compared to use switching table 3 under proposed torque controller

Figure 12 The detail of response torque ripple in steady state under proposed torque controller. 
Under Hysteresis torque controller

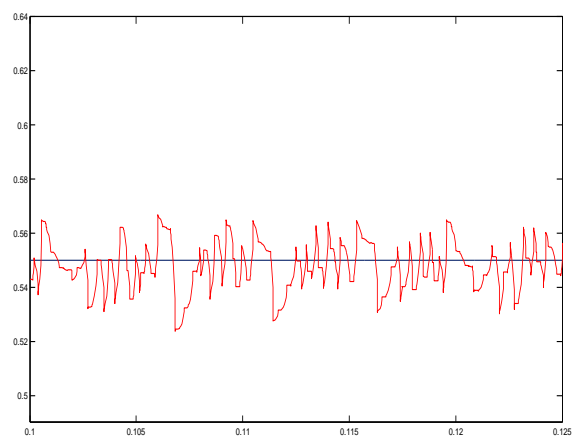

a. Using Table 1

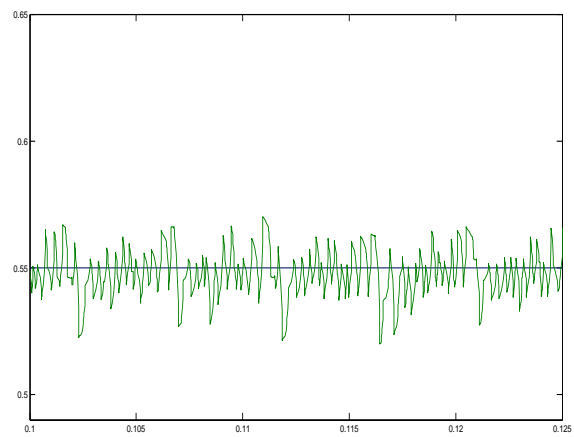

b. Using Table 2

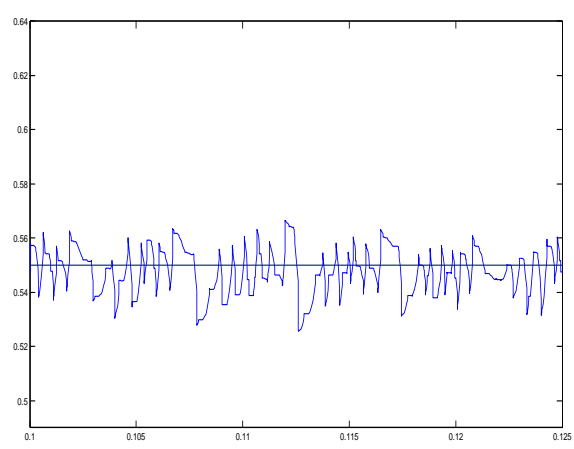

c. Using Table 3

\section{Under Proposed torque controller}

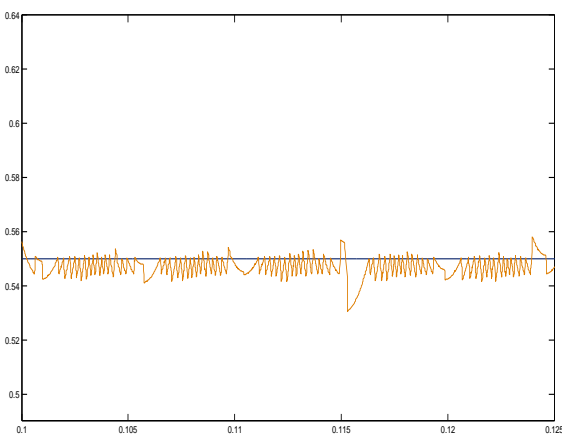

d. Using Table 1

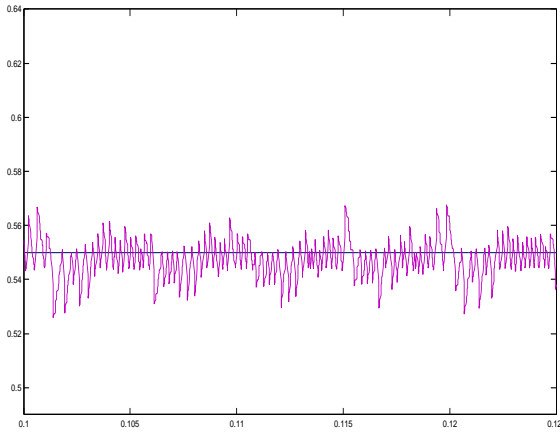

e. Using Table 2

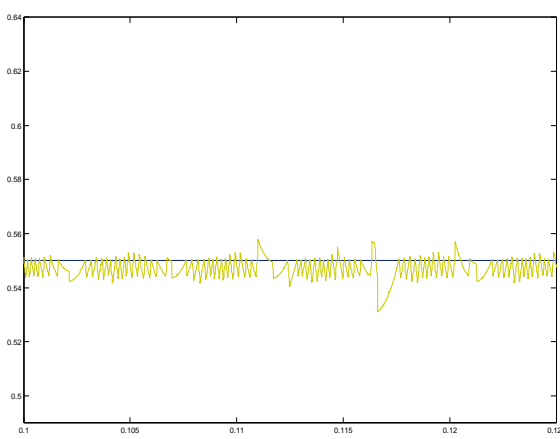

f. Using Table 3

Figure 13 The Comparison of flux response under hysteresis DTC scheme and under proposed DTC scheme use switching Table 1, 2, and 3. 


\section{Conclusions}

The paper presents simulation of a new torque controller of DTC scheme for PMSM drives. The comparisons through simulations between hysteresis DTC scheme and proposed DTC scheme for PMSM drive have been done. This simulation based on MATLAB/Simulink has represented the behaviour of DTC for PMSM drive clearly and correctly. The simulation result has shown that an almost fixed switching frequency and reduction of flux and torque ripple can be achieved through the proposed DTC scheme.

\section{References}

[1] Diamantis, G. \& Prousalidis, J.M., Simulation of a Ship Propulsion System with DTC Driving Scheme, in Power Electronics, Machines and Drives, 2004. (PEMD 2004). Second International Conference on (Conf. Publ. No. 498), 2, pp. 562-567, 2004.

[2] Bose, B., Power Electronics and Motor Drives: Advances and Trends, Elsevier Inc., 2006.

[3] Ferreira, C.L. \& Bucknall, R.W.G., Modelling and Real-Time Simulation of an Advanced Marine Full-Electrical Propulsion System, in Power Electronics, Machines and Drives, 2004 (PEMD 2004), Second International Conference on (Conf. Publ. No. 498), 2, pp. 574-579, 2004.

[4] Takahashi, I. \& Noguchi, T., A New Quick-Response and High-Efficiency Control Strategy of an Induction Motor, IEEE Transactions on Industry Applications, IA-22(5), pp. 820-827, Sept/Oct 1986.

[5] Depenbrock, M., Direct Self Control (DSC) of Inverter-Fed Induction Machine, IEEE Trans. on Power Electronics, 3(4), pp. 420-429, 1988.

[6] Zhong, L., Rahman, M.F., Hu, W.Y. \& Lim, K.W., Analysis of Direct Torque Control in Permanent Magnet Synchronous Motor Drives, Power Electronics, IEEE Transactions on, 12, pp. 528-536, 1997.

[7] Idris, N.R.N., Toh, C.L. \& Elbuluk, E., A New Torque and Flux Controller for DTC of Induction Machine, IEEE Transactions on Industry Applications, 42(6), pp. 1358-1366, Nov/Dec 2006.

[8] Jidin, A., Idris, N.R.N., Yatim, A.H.M., Sutikno, T. \& Elbuluk, M.E., Extending Switching Frequency for Torque Ripple Reduction Utilizing a Constant Frequency Torque Controller in DTC of Induction Motors, Journal of Power Electronics, 11(2), pp.148-155, 2011.

[9] Hu, Y., Tian, C., Gu, Y., You, Z., Tang, L.X. \& Rahman, M.F., In-Depth Research on Direct Torque Control of Permanent Magnet Synchronous Motor, in IECON 02 (Industrial Electronics Society, IEEE 2002 28th Annual Conference of the), 2, pp. 1060-1065, 2002.

[10] Abdul Kadir, M.N., Mekhilef, S. \& Hew, W.P., Comparison of Basic Direct Torque Control Designs for Permanent Magnet Synchronous 
Motor, in Power Electronics and Drive Systems, PEDS '07, 7th International Conference on, 2007, pp. 1344-1349, 2007.

[11] Rahman, M.F., Zhong, L. \& Lim, K.W., A Comparison of Two High Performance, Wide Speed Range Drive Techniques for Interior Magnet Motors, in Power Electronic Drives and Energy Systems for Industrial Growth, Proceedings, International Conference on 1998, 1, pp. 276-281, 1998.

[12] Zhong, L., Rahman, M. F., Hu, W.Y., Lim, K.W. \& Rahman, M.A., A Direct Torque Controller for Permanent Magnet Synchronous Motor Drives, IEEE Transactions on Energy Conversion, 14, pp. 637-642, Sep 1999.

[13] Lang, B.-h., Liu, W.-g., Zhou, X.-w. \& Li, R., Research on Direct Torque Control of Permanent Magnet Synchronous Motor Based on Optimized State Selector, in Industrial Electronics, IEEE International Symposium on 2006, pp. 2105-2109, 2006.

[14] Yaohua, L. \& Weiguo, L., Simulation Study on the Effect of Voltage Vector on Torque in Direct Torque Control System of Permanent Magnet Synchronous Motor, in Industrial Electronics and Applications, ICIEA 2007, 2nd IEEE Conference on 2007, pp. 1521-1525, 2007.

[15] Li, L., Wang, X. \& Sun, H., A Variable-Voltage Direct Torque Control Based on DSP in PM Synchronous Motor Drive, in TENCON '02, Proceedings, 2002 IEEE Region 10 Conference on Computers, Communications, Control and Power Engineering, 3, pp. 2065-2068, 2002.

[16] Tang, L., Zhong, L., Rahman, M.F. \& Hu, Y., A Novel Direct Torque Control Scheme for Interior Permanent Magnet Synchronous Machine Drive System with Low Ripple in Torque and Flux, and Fixed Switching Frequency, in Power Electronics Specialists Conference, 2002. pesc 02. 2002 IEEE 33rd Annual, 2, pp. 529-534, 2002.

[17] Lai, Y.S., Wen-Ke, W. \& Yen-Chang, C., Novel Switching Techniques for Reducing the Speed Ripple of AC Drives with Direct Torque Control, Industrial Electronics, IEEE Transactions on, 51, pp. 768-775, 2004.

[18] Lianbing, L., Hexu, S., Xiaojun, W. \& Yongqing, T., A HighPerformance Direct Torque Control Based on DSP in Permanent Magnet Synchronous Motor Drive, in Intelligent Control and Automation, Proceedings of the 4th World Congress on 2002, 2, pp. 1622-1625, 2002.

[19] Limei, W. \& Yanping, G., A Novel Strategy of Direct Torque Control for PMSM Drive Reducing Ripple in Torque and Flux, in Electric Machines \& Drives Conference, IEMDC '07, IEEE International 2007, pp. 403-406, 2007.

[20] Rekioua, D. \& Rekioua, T., A New Approach to Direct Torque Control Strategy with Minimization Torque Pulsations in Permanent Magnets Synchronous Machines, in Power Tech, 2005 IEEE Russia, pp. 1-6, 2005. 
[21] Ortega, C., Arias, A., Caruana, C., Apap, M. \& Balcells, J., Torque Ripple Reduction in PMSM DTC Drives Using Matrix Converters, in Power Electronics and Applications, European Conference on 2007, pp. 1-10, 2007.

[22] Zhuang, X. \& Rahman, M.F., Direct Torque and Flux Regulation of an IPM Synchronous Motor Drive Using Variable Structure Control Approach, Power Electronics, IEEE Transactions on 2007, 22, pp. 24872498, 2007.

[23] Gulez, K., Adam, A.A. \& Pastaci, H., Torque Ripple and EMI Noise Minimization in PMSM Using Active Filter Topology and Field-Oriented Control, IEEE Transactions on Industrial Electronics, 55, pp. 251-257, Jan 2008.

[24] Liu, T.H., Hung, C.K. \& Chen, D.F., A Matrix Converter-Fed Sensorless PMSM Drive System, Electric Power Components and Systems, 33, pp. 877-893, Aug 2005.

[25] Xu, Z. \& Rahman, M.F., Direct Torque and Flux Regulation of An IPM Synchronous Motor Drive Using Variable Structure Control Approach, in Industrial Electronics Society, IECON 2004, 30th Annual Conference of IEEE, 3, pp. 2733-2738, 2004.

[26] Yanping, X., Yanru, Z. \& Hui, Y., A Modified Direct Toque Control for Interior Permanent Magnet Synchronous Motor Drive Without a Speed Sensor, in Power Electronics and Motion Control Conference, IPEMC '06. CES/IEEE 5th International, pp. 1-4, 2006.

[27] Jun, Z., Rahman, M.F. \& Grantham, C., A New Scheme to Direct Torque Control of Interior Permanent Magnet Synchronous Machine Drives for Constant Inverter Switching Frequency and Low Torque Ripple, in Power Electronics and Motion Control Conference, IPEMC '06. CES/IEEE 5th International, pp. 1-5, 2006.

[28] Zhuqiang, L., Honggang, S., Hess, H.L. \& Buck, K.M., The Modeling and Simulation of A Permanent Magnet Synchronous Motor with Direct Torque Control Based on MATLAB/Simulink, in Electric Machines and Drives, IEEE International Conference on 2005, p. 7, 2005. 